\title{
Emergency Enterprise Marketing Strategy under the product-public opinion double crisis
}

\author{
Xingfu Shi ${ }^{1, a}$, Lingnuo Xiao ${ }^{2, b}$ \\ ${ }^{1}$ School of management in Harbin Institute of Technology, China \\ ${ }^{2}$ School of management in Harbin Institute of Technology, China \\ ashixingfuok@126.com, bhit6543@126.com
}

Keywords: products; public opinion crisis; business; marketing; contingency strategy.

\begin{abstract}
The crisis is an important factor in the formation of products with emergencies, when the product of public opinion crisis, in what marketing is directly related to the contingency strategies to achieve business goals or not. Emergency policy research under the effect of different products use public opinion crisis after consumer purchase behavior theory, the conclusion is: When high product mix of high public opinion crisis of crisis, the best excuse initiative; crisis when a high product mix low public opinion crisis, the best excuse policy initiative; when the low product mix of high public opinion crisis, a positive commitment to the best strategy; and when low product mix, low-crisis public opinion crisis, a positive commitment to excuse or active effect is no significant difference in the specific circumstances and needs set.
\end{abstract}

\section{Introduction}

When the product crisis, often accompanied by generating public opinion crisis, and then upgrade to the product emergencies. Most studies in the past from the perspective of product crisis to study business strategy to tackle the crisis while ignoring the impact of public opinion in this process. Therefore, it is necessary from the perspective of product incidents to study different scenarios contingency strategies of corporate marketing. McLaughlin (1983) corporate crisis response strategy is divided into two kinds of relaxation and deterioration, mitigation strategies is to express concern to the victims and to recognize companies fault, deterioration strategy is to protect the corporate image and deny business fault. In addition, there denied (denial) and corrected (corrective) two points method (Siomkos and Shrivastava, 1993); attack, deny, excuse, excuse, cater to, to correct, apologize seven law (Coombs, 1998). Product emergencies implementation of the object and Emergency strategy victims are consumers, changes in consumer purchase behavior is to Emergency strategy is most direct feedback. Therefore, from the perspective of post-purchase behavior to judge the merits of the emergency strategy has its direct market effect.

After narrowly purchase behavior on two aspects. Therefore, a comprehensive post-purchase behavior on the previous dimension division, can be purchased from repetition, premium payments and word of mouth of these three dimensions to discuss the impact of business contingency strategies for post-purchase behavior.

\section{Hypotheses}

When the consumer product incidents encountered, it will have two motives: revenge desire and remedy expectations. Both motivation factor is hope in different ways to make the process of resource exchange between businesses and consumers to regain balance, desire revenge after the consumer product crisis hit companies want to hurt motivation, and remediation is expected to be resolved through consultations Want to make up for the loss of motivation. Both of which lead to the opportunity to purchase after moving consumer behavior. Therefore, companies use different strategies to regulate both emergency motive, can effectively influence the purchase behavior.

According to the above inference, drawn hypothesis $\mathrm{H} 1$ : 
H1: different contingency strategies there are significant differences in the impact of post-purchase behavior.

H1a: Different Strategies on emergency post-purchase behavior differences in terms of repeat purchase is significant.

H1b: Different Strategies on emergency post-purchase behavior of the difference in premium payments is significant.

H1c: Different Strategies on emergency post-purchase behavior differences in terms of word of mouth is significant.

Purchase behavior of consumers not only from their own experience, but also to a large extent influenced by public opinion. For example, the use of consumer products in to hear their security risks, even though he did not suffer actual damage, but consumers still feel suffer a loss. Consumer perception of public opinion crisis will have a huge impact damage, thereby affecting the purchase behavior of consumers. Therefore, the strength of products for different emergency crisis and the crisis of public opinion in combination, should respond by cases.

According to the above inference, drawn hypothesis $\mathrm{H} 2$ :

$\mathrm{H} 2$ : better or worse contingency strategies exist on different impact on purchase behavior, and emergencies due to different products have different circumstances.

H2a: High product crisis, high public opinion crisis, the initiative justify $>$ positive commitment> silence

$\mathrm{H} 2 \mathrm{~b}$ : High product crisis, low public opinion crisis, the initiative justify $>$ positive commitment $\approx$ remain silent

H2c: low product crisis, high public opinion crisis, a positive commitment $>$ Active justify $>$ silence

$\mathrm{H} 2 \mathrm{~d}$ : low product crisis, low public opinion crisis, the initiative justify $\approx$ positive commitment> silence

\section{Results}

\section{1 experimental procedure}

In this paper, using four kinds of products emergency situations and three kinds of emergency strategy altogether form 12 experimental groups. Each experimental group corresponds to a specific type of emergency and a specific contingency strategies, test consumer purchase behavior under the influence (including repeat purchase, the premium payment and word of mouth).

\subsection{Scale Design}

1 defining the product types of emergencies, learn Siomkos (1994) and Vassilikopoulou (2009) scales. 2 contingency strategies and materials to match the simulation scenario. Measure 3 purchase behavior, and comprehensive reference Swan (1989), JGMaxhametal (2002) and completed the excitation force (2011) study, the repeat purchase, the premium payment and word of mouth three dimensions measured. Are all questions of Likert scale with 5 points.

\subsection{Analysis}

Sample Overview. 250 questionnaires were distributed, 34 parts excluding invalid questionnaires, obtaining 216 valid samples. Male 130, female 86, the reliability test, a good level of reliability and validity of samples, sample data follow a normal distribution.

Hypothesis Testing. Discussion (1) the overall results of the. After homogeneous test, three contingency strategy for post-purchase behavior influence the three dimensions of significant differences in the F-test data in a sample variance found: repeat purchase $(F=6.101, p=0.003)$, premium pay $(\mathrm{F}=3.361, \mathrm{p}=0.038)$, word of mouth $(\mathrm{F}=2.420, \mathrm{p}=0.093)$. With $\mathrm{p}<0.05$ as a significant test found: 1 , three emergency strategy to repurchase the impact is significant difference; (2) the impact of three emergency response strategy for premium pay differences are significant; 3 three contingency strategies to influence word of mouth spread difference is not significant;

Thus, assuming H1a and $\mathrm{H} 1 \mathrm{~b}$ be verified, it is assumed $\mathrm{H} 1 \mathrm{c}$ be rejected.

Different situations;

(1) Incident occurred after the product, measure the negative post-purchase behavior, and therefore the value of the figure of the smaller post-purchase behavior, on behalf of the policy, the better. 
In the case of low product crisis high public opinion crisis, the impact on repeat purchase, using a positive commitment to the policy was significantly better than the silence policy ( $\mathrm{M}$ bear $=0.36, \mathrm{M}$ silence $=1.19 ; \mathrm{p}=0.014)$; the use of active excuse policy significantly better to remain silent policy ( $\mathrm{M}$ excuse $=0.44, \mathrm{M}$ silence $=1.19 ; \mathrm{p}=0.001)$; affect the premium paid, using a positive commitment to the policy was significantly better than the silence policy $(\mathrm{M}$ bear $=0.64, \mathrm{M}$ silence $=1.28 ; \mathrm{p}=$ 0.034 ); the use of active policies significantly better excuse to remain silent policy ( $\mathrm{M}$ excuse $=0.97$, $\mathrm{M}$ silence $=1.28 ; \mathrm{p}=0.021$ ); adopt a positive commitment to the policy was significantly superior to justify the policy initiative $(\mathrm{M}$ bear $=0.64, \mathrm{M}$ excuse $=0.97 ; \mathrm{p}=0.041)$; word of mouth spread, the difference does not have the effect of each policy significance. Therefore, in the case of low product crisis high public opinion crisis, actively take the initiative to defend better than silence, assuming $\mathrm{H} 2 \mathrm{c}$ verified.
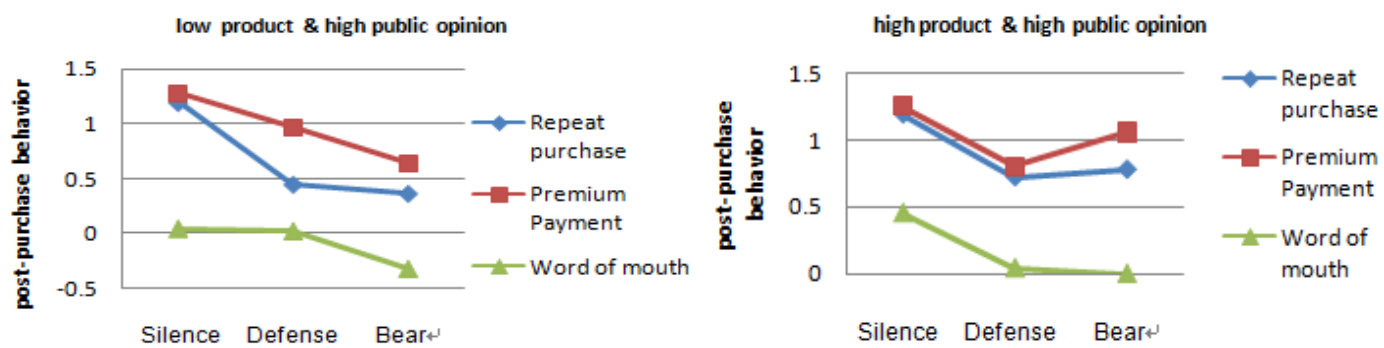

(2) In the case of high product crisis high public opinion crisis, the impact on repeat purchase, using a positive commitment to the policy was significantly better than the silence policy $(\mathrm{M}$ bear $=$ $0.78, \mathrm{M}$ silence $=1.19 ; \mathrm{p}=0.014)$; the use of active excuse policy significantly better to remain silent policy $(\mathrm{M}$ excuse $=0.72, \mathrm{M}$ silence $=1.19 ; \mathrm{p}=0.001)$; affect the premium paid, using a positive commitment to the policy was significantly better than the silence policy ( $\mathrm{M}$ bear $=1.06$, $\mathrm{M}$ silence $=1.25 ; \mathrm{p}=0.034)$; the use of active policies significantly better excuse to remain silent policy $(\mathrm{M}$ excuse $=0.81, \mathrm{M}$ silence $=1.25 ; \mathrm{p}=0.021)$; justify the use of active policies was significantly better than a positive commitment to the policy $(\mathrm{M}$ bear $=0.81, \mathrm{M}$ excuse $=1.06 ; \mathrm{p}=0.041)$; word of mouth spread, the difference does not have the effect of each policy significance. Therefore, in the case of high product crisis high public opinion crisis, actively take the initiative to defend better than silence, assuming $\mathrm{H} 2 \mathrm{a}$ verified.

(3) In the case of high product crisis low public opinion crisis, the impact on repeat purchase, using the initiative to justify the policy was significantly better than a positive commitment to the policy $(\mathrm{M}$ excuse $=0.63, \mathrm{M}$ bear $=1.14 ; \mathrm{p}=0.022)$; the use of active excuse policy significantly better to remain silent policy $(\mathrm{M}$ excuse $=0.63, \mathrm{M}$ silence $=1.28 ; \mathrm{p}=0.004)$; affecting premium payments, the use of active policies justify significantly better than a positive commitment to the policy (M excuse $=0.83$, $\mathrm{M}$ bear $=1.06 ; \mathrm{p}=0.032$ ); the use of active policies significantly better excuse to remain silent policy $(\mathrm{M}$ excuse $=0.83, \mathrm{M}$ silence $=1.31 ; \mathrm{p}=0.013)$; word of mouth spread, the difference does not have the effect of each policy significance. Therefore, in the case of high product crisis low public opinion crisis, and actively take the initiative to defend than to remain silent, assuming $\mathrm{H} 2 \mathrm{~b}$ verified.
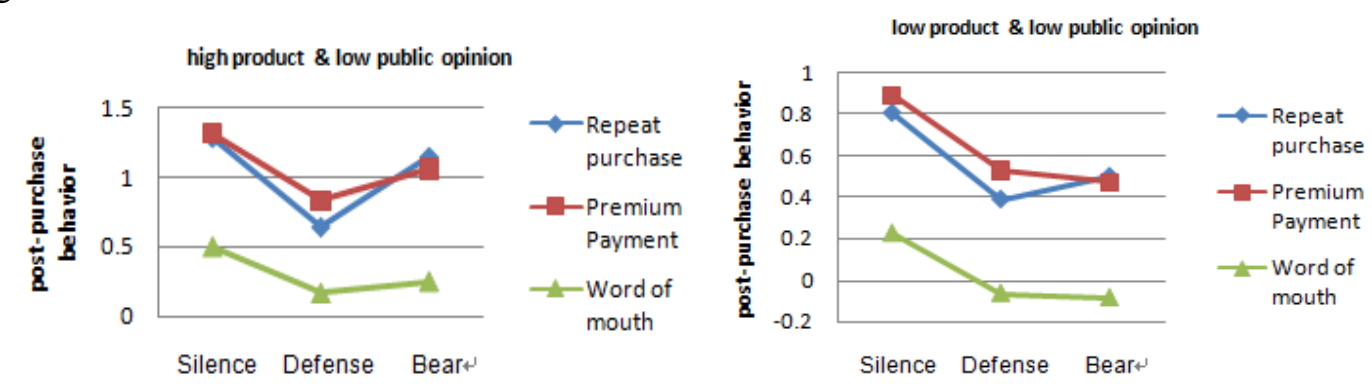

(4) In the case of low product crisis low public opinion crisis, the impact on repeat purchase, using a positive commitment to the policy was significantly better than the silence policy $(\mathrm{M}$ bear $=0.50$, $\mathrm{M}$ silence $=0.81 ; \mathrm{p}=0.027)$; the use of active excuse policy significantly better to remain silent policy $(\mathrm{M}$ excuse $=0.39, \mathrm{M}$ silence $=0.81 ; \mathrm{p}=0.013)$; affect the premium paid, using a positive 
commitment to the policy was significantly better than the silence policy ( $\mathrm{M}$ bear $=0.47$, $\mathrm{M}$ silence $=0.89 ; \mathrm{p}=0.035)$; the use of active policies significantly better excuse to remain silent policy (M excuse $=0.53, \mathrm{M}$ silence $=0.89 ; \mathrm{p}=0.041)$; word of mouth spread, the difference does not have the effect of each policy significance. Therefore, in the case of low product crisis low public opinion crisis, and actively take the initiative to defend than to remain silent, assuming $\mathrm{H} 2 \mathrm{~d}$ verified.

\section{Conclusion}

There are three conclusions: 1 , the product outbreak of unexpected events, businesses should be clear type emergencies, coupled to respond. In particular, consumers need to consider the influence of public opinion. 2, different types of products emergency, the optimal response strategies differ. When the high product mix of high public opinion crisis crisis, defended the initiative works best when a high product mix low public opinion crisis crisis, the best policy initiative excuse, when the low product mix of high public opinion crisis crisis, a positive commitment to the best strategy, and when Low product-mix, low public opinion crisis crisis, a positive commitment or active excuse is no significant difference in effect, requires a combination of specific circumstances. 3, different policies affect different dimensions of post-purchase behavior is also different, for example, in high product mix low public opinion crisis crisis, defended the use of active policies to repurchase rescue effect is particularly good; and in low product mix of high public opinion crisis crisis When using a positive commitment to save on premiums paid by the policy effect is also very good, this time accompanied by appropriate price-cutting strategy, it can largely restore the market. This study provides reference event scenario analysis for emergencies encounter products business perspective and emergency strategy.

\section{Reference}

[1] Coombs W T. An analytic framework for crisis situations: Better responses from a better understanding of the situation [J] Journal of Public Relations Research 1998,10 (3):.. 177-191.

[2] Xie Yun Geng Rong Ting microblogging evolve mechanisms to generate public opinion and public opinion to guide policy [J] Modern Communication: Communication University of China, 2011, (5): 70-74.

[3] Fu Jian Fang, Ren Yiqi companies public opinion crisis: causes, State and [J] Information Science, 2012, 31 (3): 25-28 DOI:. 10.3969 / j.issn.1002-1965.2012 .03.006.

[4] Mclaughlin M L. The Management of Failure Events: Some Contextual Determinants of Accounting Behavior [J] Human Communication Research 1983,9 (3):... 208-224.

[5] Marcus AA, Goodman R S. Victims and shareholders: The dilemmas of presenting corporate policy during a crisis [J] Academy of Management Journal 1991, 34 (2):... 281-305.

[6] Siomkos G, Shrivastava P. Responding to product liability crises [J] Long Range Planning 1993, 26 (5): 72-79.

[7] Wang Xiaoyu, Chao steel orders, etc. Wu era harm crisis and its impact on consumers consider the process set [J] Management World, 2006, (5): 86-95.

[8] Bi vibration force, Yuan Denghua purchase behavior dimensions and Difference: Based on different consumer situations [J] Soft Science, 2011, 25 (8):. 139-144 DOI:. 10.3969 / j.issn.1001-8409.2011 .08.030.

[9] Luo Xiaoguang, to stand customer satisfaction and customer purchase behavior relationship [J] Management World, 2007, (6): 166-167.

[10] Herr PM, Kardes FR Kim J. Effects of Word-of-Mouth and Product Attribute Information on Persuasion: An Accessibility-Diagnosticity Perspective.Journal of Consumer Research.1991,17: 454-462. 